\title{
Read This Book Out Loud: A Critical Analysis of Young Adult Works by Artists from the Poetry Slam Community
}

\author{
Adam D. Henze
}

\begin{abstract}
This article examines the efforts of notable authors from the poetry slam community who have published Young Adult works intended for the classroom. Numerous secondary educators have embraced spoken word poetry as an engaging art form for teenagers yet often express difficulty in finding age-appropriate material to share in school settings. This literature review hopes to serve as an introductory reference for secondary educators and researchers, and differs from slam-themed reviews in that it specifically highlights artists from the slam circuit who have transitioned into YA publishing. Since the featured authors hail from backgrounds in theatre and performance, the works discussed often incorporate characteristics of oral verse that seemingly transcend the print medium. Also examined is the inherent barrier between oppositional, profane narratives embraced by youth, and the expectations of educational institutions who use censorship to sterilize places of learning. Written by an educator and academic who has been a part of the slam community for over a decade, this article offers an insider's perspective for secondary educators, researchers, and fans of spoken word poetry who wish to know more about integrating the works of prominent 'slammers' into their classroom curricula.
\end{abstract}

Keywords: poetry slam; young adult literature; literacy; spoken word pedagogy; reading; censorship

\section{The Poet That a Young Me Needed}

Whenever I find myself standing in front of a cafeteria or gymnasium filled with hundreds of secondary-aged students, my arms spread wide like I'm suspended on a high dive, I always think about how badly I needed a good poet in my life when I was fourteen. Instead, I learned to write by carving on my arm with twisted staples. I learned to speak by shrieking obscenities at my teachers. The first day I can remember not wanting to die came a couple years later when I was introduced to a book called Aloud: Voices From the Nuyorican Poet's Café. For many spoken word enthusiasts around the world, the phonebook-sized tome of poems was the first glimpse at a radical new vehicle for performance art called poetry slam. Emotional and raw, with content ranging anywhere between confessional testimonials, political assaults, raunchy stand-up comedy, and hiphop holler-if-you-hear-me flows, the poetry chronicled in Aloud reinvigorated a public interest in performed verse (Kaufman, 1999). A large part of that public interest was kids 
like me (Weiss \& Herndon, 2001). When I was sixteen I stopped writing drafts of my suicide note and I started writing poems.

Those are the memories I think about, fifteen years later when I'm rapid-fire whipping words at crowds of school kids. I became the poet that a young me needed, a move similarly made by thousands of artists who transitioned from the slam scene to the classroom. Since Aloud's publication in 1994, numerous educators have recognized the immediate benefits of introducing performance poetry in the classroom (Holbrook \& Salinger, 2006), particularly noting the medium's ability to engage reluctant readers (Low, 2011). Despite the increased desire to use what is often simply called spoken word in classroom settings, many educators outside the slam community are uncertain how to introduce slam into their lesson plans beyond playing a short video or inviting a practitioner like myself to class for a one-time performance. The blame need not rest solely on the shoulders of uninformed secondary-school teachers; although slam academics have approached spoken word as a writing pedagogy (Fisher, 2007) and a performance pedagogy (Sibley, 2001), relatively little research has been published that approaches slam as a reading pedagogy.

In the foreword of Aloud, coeditor Bob Holmon (1994) declares, "DO NOT READ THIS BOOK. You don't have to. This book reads you. This book is a SHOUT for all those who have heard the poem's direct flight from mouth to ear. Hear this book with your eyes! When the Mouth marries the Eye, the Ear officiates" (p. 1). This self-professed "invocation" points to spoken word's ability to transcend the page. Many slammers record their work in audio or video in lieu of the traditional print medium; however, educators would be surprised to learn how many notable artists have published their poems in literary journals, anthologies, and as collected works on small and large presses (Somers-Willett, 2009). And although New Literacy proponents commonly use the audiovisual work of slammers to meet newly imposed digital literacy standards (Brawley, 1994; Harlan, 2008), nearly every practitioner from the slam community that I have collaborated with insistently uses textual analysis as part of their spoken word pedagogy. Just because the works are multimodal does not mean that the print form needs to be excluded (Michael, 2001).

Understandably, this textual barrier has resulted in a low number of opportunities for slammers to create age-appropriate literature ideal for use in classroom reading instruction. By reviewing the few examples of print-based literature written specifically for young adult audiences, this article aims to serve as an initial effort to establish slam as a reading pedagogy. In an attempt to create a familiar ground for instructors of literacy, I will draw comparisons between poetry from the slam circuit and common conventions found in young adult literature. By identifying the similarities between spoken-word pedagogy and pedagogies typically associated with young adult literature, I hope to give literacy educators a foothold for approaching slam through typical means such as textual analysis, group discussion, and short written responses. After exploring the history of slam's "spoken word revolution" (Eleveld, 2003), analyzing the beneficial characteristics of the art form, and addressing some of the barriers practitioners have faced using slam in the classroom, I believe educators curious about using slam will have a better understanding of the pedagogical aspects of the medium. This literature review also dually serves as a 
resource for educators who want exposure to more slam artists and as a plea for young adult book publishers to collaborate with accomplished authors from the global slam community.

\section{Themes Shared by Slam and Young Adult Literature}

To begin, many educators mistakenly refer to slam as a genre, when in fact it is more of a mechanism. In 1986 a Chicago construction worker named Marc Smith decided to drastically change the way we experience poetry. Academic practices such as New Criticism had alienated casual patrons of performed verse (Gioia, 2002), and Smith fought back by devising a populist contest where competing poets faced off in front of rowdy blue-collar bar patrons (Smith \& Kraynak, 2004). Some audience members were given score cards to judge each performance, while others were encouraged to cheer for the poets they loved and boo the poets they did not. Though it began as a quirky game in an Uptown pub, poetry slam exploded into a worldwide literary movement in the mid-nineties after it garnered the attention of mainstream entities such as MTV, Lollapalooza, NPR, and HBO (Aptowicz, 2008). More notably, teens around the world came to embrace slam as a powerful avenue for self-expression (Erlich, 1999).

Since scholars are at odds regarding whether slam competitions have spawned an actual genre known as slam poetry, many proponents such as myself simply refer to poems used in slam as spoken word. Considering that spoken word has reached young readers from countless backgrounds and cultures (Poole, 2007), it is not surprising that poetry used in slam shares numerous conventions with the characteristics of young adult literature. By establishing such connections, educators should feel empowered to draw upon their literacy instruction skill set to form their own unique methodology for reading the poetry of slammers in classroom settings.

First, poetry slam's initial aim was to reject the cryptic nature of academic verse by crafting lyrical content that utilizes "common language" more familiar to everyday audiences (Ellis, Gere \& Lamberton, 2003). In a 1988 New York Times article-one of the first major newspapers to cover the then-new slam thing-Marc Smith famously quipped "Hifalutin metaphors got no place here" (Johnson, 1988). Holman echoed Smith's cry, claiming that slam began as an attempt to return written verse back to community spaces by "mak[ing] poetry as natural a use for language as ordering a pizza" (Aptowicz, 2008, p. 10). Many slammers accomplish this task in their verse by utilizing colloquial speech, slang, and non-English phrases spoken in the home (Fisher, 2007). Numerous educators have singled out this characteristic as a critical way to revitalize the stale, antipodal material of traditional poetry units: "We think the problems teachers face with teaching poetry can be addressed by making its oral nature more visible and audible to students" (Ellis et al., 2003, p. 44).

Second, like the underdog main characters in many young adult works, the spokenword medium often showcases protagonists with marginalized identities (Lacatus, 2009). The open format of slam encourages all participants to share their own story, which essentially promotes the voices of traditionally muted groups and allows writers to feature elements of their unique cultures and backgrounds in their attempts to construct a literary identity (Biggs-El, 2012). An ethnographic study of a youth poetry slam team in Ohio 
revealed that participants referred to themselves as having "outlaw identities" (Rudd, 2012), while in another study participants of a youth writing group in the Bronx claimed they adopted a "blues singer identity" (Fisher, 2007). In both case studies young learners from diverse backgrounds used identities constructed in the writing process to form a familial bond, thus developing a literacy community. Slam scholar Susan Somers-Willett (2009) explains that slam participants often use humor and culturally rich themes to align themselves with the audience, a desired dynamic for young readers yearning for relatable protagonists in classroom reading materials.

Third, similar to the many popular socially aware young adult novels, a substantive number of slammers use spoken word as a way to address critical issues that affect their local and global communities (Stovall, 2006). Ingalls (2012) explains, "The spoken-word venue becomes a forum in which participants assert and defend the legitimacy of their social and political views, and the audience is a critical component in the exchange of ideas; their responses to the messages they see and hear help to spark and sustain dialogue, and to validate the voices of youth" (p. 101). In their own study, Bruce and Davis (2000) noticed a commonality in the background knowledge of their students: teens in the classroom were familiar with both the conventions of hip-hop and the grim realities of systemic violence. By using spoken word as a conscious alternative to hip-hop (Aptowicz, 2008), students can address issues including racism, gun violence, gang warfare, poverty, and drug dependency in a way that allows their words to function as an agent of change (Bruce \& Davis, 2000).

\section{“Please Don't Cuss. Please Don't Cuss. Please... Dammit."}

Considering the similarities between slam and young adult literature, it would seem that spoken word is a perfect fit for classroom reading. However, many educators who are unfamiliar with the populist aesthetics of spoken word have run into pitfalls when attempting to use performance poetry in the classroom. As is, when an educator hears a performance poem they think will resonate with students, typically they have to follow a similar mundane process: manically combing over every word in every line, praying the artist doesn't swear or say something vulgar that would "disqualify" the poem from potential use (despite any positive content the poem has to offer). This procedure is an indicator of the few inherent barriers to using poetry in the classroom that was originally written for an adult slam audience. Before delving into our review of age-appropriate literature written by slammers, I felt it would be beneficial to analyze three texts written for the adult market in order to give educators a better understanding of the barriers they need to look out for. Arguably, an analysis of these texts will also demonstrate the malleability of the form, and will highlight some of the unique characteristics of transferring poems from the oral medium to the written page.

On one end of the spectrum is a novel written entirely in verse: Stickboy, by Canadian poet Shane Koyczan. In this semiautobiographical work, the reader is exposed to the seething emotions experienced by the author when he was bullied as a child. Koyczan's school-aged protagonist matches several conventions of young adult characters: he is an orphan, raised by his grandmother, misunderstood by his teachers, learning to stand up to a world that seems entirely against him. In a dramatic retelling chock full of figurative language, the novel takes an unexpected turn when the protagonist snaps and becomes the 
one thing he despises most-a bully. The novel showcases vivid metaphors that help the reader digest the complexities of violence and abuse: I was mechanical now / with an autopilot that had grown restless / after a decade-and-a-half of being set to defense. // The once-solitary fortress of my mind / had built for itself tank treads / and it slowly rolled forward to attack (Koyczan, 2012, pp. 125-126). The text also highlights more visceral passages by displaying them on a separate page, often changing the size and style of the font. Likely an attempt to capture spoken word's dynamic nature in lieu of using common conventions of orality such as change of volume and use of gestures (Ellis et al., 2003), analyzing similar typographical considerations could be beneficial for linguistic and spatial learners (Gardner, 1983). Ultimately, the text demonstrates Koyczan's efforts to advocate for the antibullying movement, an act that showcases a slammy characteristic set apart from conventional poetry in that its content often ends with a call to action (Smith \& Kraynak, 2004). Koyczan's activism is evident in many of his works, which may function as supplemental texts for lesson plans focused around Stickboy: his Ted Talk presentation To This Day ... For the Bullied and the Beautiful juxtaposes coming-of-age-anecdotes, metaphors about playground politics, and expository speech that seamlessly transitions to a live performance of his narrative poem To This Day.

A separate video of the poem To This Day went viral in 2013-with thirteen million views to date-due to the efforts of the To This Day Project which tasked over eighty animators to illustrate separate portions of Koyczan's confessional verse, accompanied by seven musicians who created orchestral music to accentuate the dramatic arcs of the poem. By scaffolding the shared themes of the two videos to Koyczan's longer work Stickboy, educators can create a brave unit that succeeds in fostering productive discussion and reflection on violence in schools. A few barriers prevent me from parading this book in every classroom I visit. First, although Koyczan rarely uses profanity in his poems, the few f-bombs he does drop have a crater-sized impact. Second, Koyczan's immersive use of figurative language may require instructional support, which could make casual student reading difficult. Third is accessibility. In my own search, a paperback copy of the book was available exclusively on his website for $\$ 19.95$, with another ten going toward shipping costs from Canada. While I am happy that the artist received a majority of the profit from my individual purchase, I struggle to imagine a classroom buying a case full of copies at thirty bucks a pop.

In the middle of the spectrum is a collection of short essays and poems by Carlos Andrés Gómez entitled Man Up: Cracking the Code of Modern Manhood (2012). Part memoir and part self-help book, Man Up critiques the toxic conventions that young boys are often taught in our society, such as reverence for war culture, homophobia, entitlement in sexual relationships, and the various implications involved with being a young man of color. While the conversational language of each essay uses few figurative elements typically found in verse, the beginning and end of each chapter are punctuated with topically themed dramatic monologues and spoken word poems. Accentuated by shifts from line break to prose paragraph, Man Up essentially presents itself as a woven collection of vignettes that Gómez uses to construct a multifaceted identity in front of the reader. One chapter features the stories of an elementary-aged boy, Carlitos, living in Colombia as an American expatriate, where the author's childhood self learns a lesson about gender roles after his aunt scolds him for painting his fingernails with his sisters. In another chapter detailing his 
middle school years living on America's East Coast, a young Carlos learns that his status as a light-skinned Latino can sometimes grant him privileges not often afforded to his male friends with darker complexions. Gómez's intersectional identity is often conveyed through his liberal use of casual speech, slang, and phrases in Spanish. In a particularly memorable anecdote, Gómez recollects a time as an adult when he was invited to perform his poetry for the residents of Riker's Island penitentiary. The scene comes to a crescendo when Gómez approaches a young man in "tight cornrows" with "deep brown eyes," saying "Hermano, we aren't what we call each other. / Hermano, we've lost too many of us already. / Hermano, me llamo Carlos. Ya nos conocemos" (p. 8). Like Stickboy, the content of Man Up lends itself well to classroom discussions of issues revolving around aggression, masculinity, and self-esteem.

The main barrier of using this text in some classrooms is the point where Gómez's use of familiar terms exceeds the restraints of appropriate language allowed in certain learning communities. For example, the chapter called Guys' Club: No Faggots, Bitches or Pussies Allowed critiques the pejorative terminology that boys are often taught to use against each other at a young age. While discussion on such language is certainly warranted, the conversation forces educators to confront an uncomfortable dichotomy in their classroom: how do you critique inappropriate terms and behaviors in a learning environment that limits language use? Gómez's (2012) poem "What is Genocide?"available in text form in the book and as a video recorded for HBO's Def Poetry posted on YouTube-confronts this stalemate of an issue by reenacting a conversation where a principal discouraged the author from using poems with profanity in the classroom: "They won't let you hear the truth at school / if a person says fuck. / Can't even talk about fuck even though / a third of your senior class is pregnant" (p. 203).

At the far end of the spectrum is a fictional novel of prose called Ready Player One (2011) by slammer and screenwriter Ernest Cline. Packed with references to Atari video games, comic book superheroes, and Star Trek episodes, the fantasy/sci-fi novel stands as a homage to nerd culture via its use of a common convention in postmodern stand-up verse: reverent allusion to pop culture phenomena (Eleveld, 2003). In the dystopian tale, we meet underdog character Wade Watts, an orphaned adolescent living in poverty with his aunt in a desolate neighborhood comprised of clusters of fused mobile home shells stacked upon one another. Overweight and insecure about his physical appearance, Watts uses his slightly thinner, definitely cooler online avatar Parzival to reconstruct a preferred identity in a not-all-that-futuristic escapist virtual world called OASIS. While the text uses far fewer figurative tools than Stickboy and Man Up, Cline's narrative is reminiscent of a popular form of cultural sharing in the slam community called "the nerd slam" (Aptowicz, 2008), a safe space where superfans can recite poetry declaring their love for Pokémon and Battlestar Galactica free from the fear of lunch money gankings and atomic wedgies. For this reason, Ready Player One seems special in its ability to appeal to school-aged male gamers and comic book fans who often feel discouraged from discussing their favorite literary characters in traditional classrooms. The book utilizes common language through its use of Internet jargon and other tech-head conventions (such as depicting dialogue as a chat window). Like other dystopian young adult novels, the narrative also raises questions about the implications of approaching an "always online" world. The antagonist force in the 
story is a conglomerate group called the Sixers-a greedy corporate entity hoping to privatize the free-to-play online utopia the spoiled Earth knows as OASIS.

The Massive Multiplayer Online game becomes an allegorical metaphor for society's varied attempts to escape from a nonideal world. For example, Wade is shocked when he finally meets his lifelong online friend Aech in person; instead of resembling the physically fit, white male avatar Wade knows, Aech turns out to be a husky African-American teenager named Marie. Although Wade initially feels betrayed by Marie's online switcheroo, he comes to understand that his friend has constructed a Eurocentric avatar to escape realworld prejudice. "From the very start, Marie had used a white male avatar to conduct all of her online business, because of the marked difference it made in how she was treated and the opportunities she was given" (Cline, 2011, p. 320). The inherent barrier of introducing this text in the classroom is that although it is written in the style of a young adult novel, its 80s-centric references to Monty Python skits and the Back to the Future films seem more tailored to forty-something nerds from the eight-bit era. However, when combining Ready Player One with spoken word poems and digital components found on Cline's website, educators can create a geektastic text set sure to pique the interests of superfans eager to learn more of nerd culture.

In retrospect, although each book contains language that disqualifies it from being considered young adult literature, it is difficult to imagine that these texts were created without young readers in mind. Each work functions as a coming-of-age narrative, features a school-aged protagonist, promotes the voices of young people, and models ideal behaviors necessary for making the world a better place. And while the supplemental inclusion of topical audiovisual short works promotes the creation of multimodal authorcentered text sets, some educators simply cannot get past the often explicit nature of the art form. Perhaps this clash gives credence to the fear that the culture-rich, populist vehicle of poetry slam may never fit neatly within academic institutions (McDaniel, 2000), which tasks educators with weighing the costs and benefits of introducing emancipatory literature in a structured setting. If your school is typically policed by reactionary parents and administrators, it may be a safe bet that using poetry from the adult slam circuit could be a problematic addition to a conservative classroom curriculum.

\section{Young Adult Literature from Slam's First Wave}

While most spoken-word pedagogues use poetry plucked from the adult slam circuit, a few slammers have succeeded in crafting age-appropriate literary texts written specifically for use in secondary instruction. The use of said works is beneficial to traditional educators because it circumvents many problems of using poetry written for mature audiences. This review hopes to promote an underserved arts community that desires increased representation in the established young adult literature marketplace.

Although slam has thrived in underground bars and coffee shops since its inception in the mid-80s, a market where slam artists could make a living never really appeared until 1996 when corporate media outlets like MTV gave their attention to the booming literary scenes popping up in cities such as New York and San Francisco. Poet and slam scholar Cristin 0'Keefe Aptowicz refers to this preprofessional era as slam's First Wave (2008). One such pioneer from this time is a poet named Allan Wolf, whose organizational efforts were 
vital in helping establish slam as the sustainable grassroots community we know today (Abbott, 2008). Like many poets from the First Wave who viewed slam as a temporary stepping stone for writers (Aptowicz, 2009), Wolf eventually left the competitive slam circuit to pursue a career as a full-time author and educator. What sets Wolf apart from most of his peers from the era is that his efforts as an artist have focused almost entirely on crafting poetry for children and young adults.

Wolf is the author of two "middle-grade" novels categorized as historical fiction: New Found Land (2004), which details Lewis and Clark's epic journey to find America's rumored Northwest Passage to the Pacific Ocean, and The Watch that Ends the Night (2011), which documents the maiden voyage and final moments of the RMS Titanic. Meticulously researched and accompanied by lengthy appendix sections, both $450+$ page collections follow a similar template of one- to two-page-length poems told from the firstperson perspective of witnesses to each historical event. A common writing convention in the slam scene is the use of the persona poem; slam icon Patricia Smith (2000) explains, "in a persona poem, the writer eliminates the middle man and actually becomes the subject of his or her poem. The voice is both immediate, and immediately engaging. In the best cases, the poem's audience is drawn into a lyrical narrative by someone they want to know better-a taxi driver, Little Richard, an undertaker" (p. 71). Wolf answers Smith's challenge literally by ending each chapter with a poem from the perspective of Jon Snow, the undertaker tasked with identifying the bodies who died in the Atlantic Ocean. While space in the books is dedicated to notable characters like Sacagawea and the Unsinkable Molly Brown, Wolf spoke in an interview about his authorial intent, "I wanted to know what the story was from all the people behind the scenes. The ones that are in the background" (Wolf, 2012). In New Found Land we are privy to the thoughts of William Clark's slave York, who observes how Clark goes to great lengths to ensure no "family men" enlist for the voyage, yet forces the servant to leave his wife and children behind.

Slammers often approach the exercise of the persona poem in a unique way by giving anthropomorphic voice to animals and inanimate objects (Smith, 2000). The title New Found Land is a tongue-in-cheek reference to the Newfoundland dog owned by Meriweather Lewis; the shaggy pup's internal monologue serves as the dominant narrative thread that ties the collection of poems together. In fact, Wolf juxtaposes the dog's observations of being property owned by a master with York and Sacagawea's own critiques of bondage, which could serve as a catalyst for in-depth issue-based classroom discussion on America's history of slavery and colonialism. In The Watch that Ends the Night, a poem from the perspective of a ship rat scatters spatially across the page and the tight rhyming lines from the iceberg slowly drift in ominous warning: "I am the ice. I see tides ebb and flow. / I've watched civilizations come and go, / give birth, destroy, restore, be gone, begin" (Wolf, 2011, p. 7).

The books utilize common language in a multitude of ways: In New Found Land, the scene where the Corps of Discovery reaches the Pacific Ocean is told in a multivoiced poem, woven with onomatopoeic words and colloquial turns of phrase. The Watch that Ends the Night betrays spatial expectations readers have of the page when the print of Morse code messages fades lighter and lighter, and when the last words of shipbuilder Thomas Andrews sink off the paper like the drowning Titanic. As the hulking ship slips into the 
Atlantic, the reader turns the page to discover a sucker punch of a concrete poem: a thrashing pile of italic phrases such as god help us and you'll kill us all pool around the center of the page, peppered with words like frío, kälte and cold to represent the frigid cries of the immigrant third class passengers. Surrounding the word pool are clusters of fourline excerpts of a poem called The First Class Promenade, which serves as an eerie representation of the lifeboats where spared passengers like Margaret Brown were left to helplessly watch their poorer shipmates die. It seems such a waste that there aren't more creative books of verse based on historical events because texts like these could be a godsend for social studies instructors hoping to embed whole-language instruction into their classroom.

A departure from Wolf's content-based poesy is the young adult novel Zane's Trace (2007). A heroic epic in the style of a stream-of-consciousness road-trip novel, the booklength poem reads like the sequential entries of a poetry journal penned by a teenage boy driving cross-country to the gravesite of his mother. Coming to grips with his mother's recent suicide, our protagonist Zane uses written verse to formally question the rigidity of his own fleeting mental state-a warranted assessment considering the impulsive exodus, stolen car, and loaded gun he's stashed the glove box. An introvert with few friends and tendencies for creative escapism, Zane resembles the outlaw archetype many young slammers construct through the writing process (Rudd, 2012). The one- to five-page chapters are labeled as mile markers along the historic Zane's Trace highway, which serves as an allegory for Zane's transcendental search to trace the origins of his identity. Our protagonist's ability to tell the story is confounded by schizophrenia and grand mal epilepsy, and Zane's calls for guidance are answered as he is visited by hallucinations of ancestors from his multiethnic bloodlines. Zane's Trace incorporates common language through pattern and repetition by visually representing Zane's synesthesia-a neurological condition of the senses where individuals may ascribe a taste to a certain word or see a sound represented as a color (Spasic, Lukic, Bisevac \& Peric, 2012). Zane's synesthesia takes the form of spatial mantras that weave in and out of the narrative almost like the reprise of a piece of music. Give my mother back her mind. / Calm the demons in her head. / Leave the darkness far behind. / If need be, take me instead (Wolf, 2007, p. 6). The closer our protagonist gets to Zanesville, the more his internal monologue touches on the topic of suicide. Recent high-profile incidents have begged the need to discuss suicide and mental illness with young learners in our schools, and the relatable antihero of Zane's Trace could be an effective way to start a complex classroom conversation on the topics of mental health and self-esteem.

Closing out Allan Wolf's catalogue is a 64-page novella titled More Than Friends: Poems from Him and Her, coauthored with another poet from slam's First Wave era named Sara Holbrook. Holbrook's path differs from Wolf's in that she was an established children's book author first before transitioning second to the slam community. Slammers active in the early 90 s participated in a time before slam became its own homogenous cultural entity, so a lot of the First Wave was popularized by writers, musicians, and performers with more varied artistic backgrounds (Abbott, 2008). If nothing else, Holbrook's success in both the slam and young adult literary circuits suggests that the two have many shared conventions. As the subtitle of the book implies, More Than Friends uses a dueling narrative to tell the story of two high schoolers' first romantic relationship (Holbrook authored the 
point of view of the girl and Wolf wrote the point of view of the boy). The shuffling efforts of the two unlearned adolescents in the book are made instantly relatable by our access to the characters' inner monologue. In a tanka called "Foolish," Wolf (2008) writes, "My fly was open. / Spilled our popcorn on the floor. / Stepped on your foot-twice. / Yet the more the night went wrong, / The more you and I felt right" (p. 26). The dueling-author approach forces the reader to stretch their empathetic reasoning, as the young couple's relationship waxes in poems like "Making the First Move" and wanes in poems like "Do Not Bolt Screaming, Clutching All Your Stuff." Holbrook and Wolf give authentic voice to their protagonists by making the speech choices of teenagers: "I hope she likes the way my blue jeans sag - / the boxer shorts exposed. The belt bum-wrapped. / I wear 'em inside out to show the tag: / DKNY-Hilfiger-Nike-Gap" (Holbrook \& Wolf, 2008, p. 18). The multivoiced poems beg to be read out loud, which could produce some fun reader's theatre exercises in the classroom. Many of the poems are written in traditional forms like tanka, sonnet, and villanelle, with a short instructional appendix to assist young writers who want to learn the conventions of traditional verse. The book could serve as a catalyst for formbased writing responses about sex, young love, consent, and the heartache involved in breakups. An author's note from Holbrook and Wolf concedes that they cannot speak for the feelings of all young men and women, which suggests that the authors would be open to instructors using their text to spark a conversation about gender roles and nontraditional relationships.

In addition to a lengthy catalogue of picture books and collections of children's poetry, Sara Holbrook is also the author of one tween-aged book of verse called Walking the Boundaries of Change (1998). Subtitled Poems of Transition, the cover of the book depicts a pair of legs-familiarly clad in rolled blue jeans and Chuck Taylor All Star sneakers-pensively walking a tightrope in the foreground of swollen storm clouds. Lending authentic voice to the anxious uncertainties many adolescent readers can identify with, Holbrook uses a common convention in stand-up poetry called confesssionalism. Authors of confessional verse typically give voice to issues plaguing their personal lives, first popularized by Sylvia Plath's poems on suicide and Robert Lowell's poems about his deteriorating marriage (Rosenthal, 1959). In the poem "A Different Fit," Holbrook (1998) uses first-person narrative to articulate the awkward feelings of preteens experiencing physical changes brought on by puberty: "Today / I want to fit in / another speck in the sparrow crowd. / Not be perched like ostrich hiding / with embarrassing parts sticking out" (p. 8). Employing a lens popularized in second-wave feminist thought, Holbrook's protagonists use Carol Hanisch's (1970) concept of "the personal is political" to examine how large-scale issues manifest themselves in the personal experiences of the individual. In her poem "Blown Away," Holbrook uses street speech to tell the story of a boy named Tony whose dress and slang are the envy of the entire school. When Tony inevitably joins a gang, which swallows up the individuality his classmates once admired, Holbrook addresses the issue of urban tribalism as it manifests through the experiences of young people. Whereas many young adult novels focus on crafting supercharacters who exhibit desirable behaviors and execute world-saving decisions, Walking the Boundaries of Change creates a space where young readers can approach life issues therapeutically alongside Holbrook's characters, with little attention paid to formulating strategies for solving life problems. The poem "My Plan" features the perspective of an adolescent girl vocalizing the insecurities 
she feels about her physical appearance-detesting her beak nose, big feet, and Minnie Mouse voice. While many young adult authors might feel compelled to teach this protagonist a lesson in self-acceptance, Holbrook instead allows the character to air her grievances in an environment free from judgment and recourse. Although permitting honest discussions can be a difficult activity for educators quick to give advice, allowing young people a safe space to express themselves is in itself a thoroughly political act.

Like the adult texts analyzed in the previous section, Wolf and Holbrook use live performance and digital resources to make the reading of their poetry a multimodal learning experience. Additionally, since these First Wavers were pioneers in introducing slam to traditional classroom settings in the mid-90s, Wolf and Holbrook have each written several instructional texts to aid educators hoping to practice spoken-word pedagogy in their schools. While uniquely talented in their own right, the successful efforts of Wolf and Holbrook suggest that artists from the untapped poetry slam community could produce powerful texts for teens.

\section{The Later Waves Have Their Say}

In 1996, poetry slam exploded into a mainstream global phenomenon, meaning that poets from the Second Wave did not have to leave the slam circuit to make a living as an artist (Aptowicz, 2008). Perhaps it is for this reason that few slammers have made the transition to the young adult market. However, a major characteristic of slam's Third Wave has been a resurgence of small press publishers, giving a few spoken-word practitioners the chance to create texts ideal for reading instruction in secondary schools. Possibly the most successful independent press featuring artists from the slam community, Write Bloody Publishing, was created in 2004 by Second Wave slammer Derrick Brown after he observed that many career poets still relied on Kinkos to personally craft their own shabby chapbooks to sell on tour. Although primarily a publisher of adult-market poetry and prose collections, Write Bloody has released two collections of poetry for young adults: Learn Then Burn, and Courage: Daring Poems for Gutsy Girls.

The cover of Learn Then Burn depicts a flaming book sitting on top of an empty classroom desk, beside the words A modern poetry anthology for the classroom inscribed within a sunflower seal. Edited by Chicago teacher and poet Tim Stafford and Write Bloody owner Derrick Brown, Learn Then Burn features classroom-friendly poems by dozens of poets on the slam scene-including fan favorites such as Buddy Wakefield and Shira Erlichman. Some poems are original works written specifically for the publication; others are popular poems edited for content, such as Anis Mojgani's (2010) poem "For Those Who Can Still Ride an Airplane for the First Time: I'm 31 years old and I'm trying to figure out most days what being a / man means. / I don't drink fight or love / but these days I find myself wanting to do all three" (p. 82). Fans familiar with the poem will recognize that the editors substituted the euphemism 'love' for another four letter word. Vocalizing what many teenage boys may experience as they grow to question societal expectations of manhood, Mojgani's sobering tone could provide an open door for classroom discussion on gender roles and masculinity. Several authors in the anthology adopt the voices of their younger selves in order to address issues important to young adults. Cristin O'Keefe Aptowicz's "Benediction for Prom Night" gives voice to a young girl's anxieties as she 
prepares her hair and makeup for the prom, while Geoff Trenchard's "Pox" depicts a teenage boy's inner monologue as he examines his acne-inflicted complexion in the bathroom mirror. To help bring the poem to life, an audiorecording of a live performance of "Pox" is available on an online site called IndieFeed-a performance poetry podcast featuring an archive of thousands of poems. With material ranging from hip-hop sonnets to 8-bit Nintendo odes to zombie persona poems, the verses featured in Learn Then Burn use digestible language to address topics that kids care about. A separate Teacher Guide \& Workbook Companion is also available as a resource for educators, edited by Stafford and fellow public school teacher and slammer Molly Meacham.

A recent release from April 2014, Courage: Daring Poems for Gutsy Girls is labeled for ages "twelve to twenty-one," as "a fierce collection of poems for anyone who is, or has been, or knows a teenage girl." Featuring the work of thirty-three women-all prominent artists on the slam scene or in peripheral literary circles-the anthology contains works original to the publication and selected works from other Write Bloody titles. Edited by an allwoman team of Second Wave slam vets Karen Finneyfrock, Rachel McKibbens, and Mindy Nettifee (2014), Courage showcases poems that tackle issues important to girls such as body image, sexual assault, gender roles, and motherhood. Addressing the brightline between emancipatory spoken word and the confines of the traditional classroom, a letter from the editors states, "These are the poems we wish we had had when we were younger. They're not all easy or 'classroom friendly'" (Finneyfrock, McKibbens \& Nettifee, 2014, 17). This concession puts the burden on educators to select works they themselves deem both appropriate and relevant for their own classroom community. Like Learn Then Burn, several authors in Courage adopt a reflective voice to address topics important to their younger selves: in the poem "Pretty," Shanny Jean Maney uses a humorous tone to reminisce about her awkward attempts to match the "beautificiality" standards of Vanna White and Miss Piggy, while in the poem "A Letter to the Playground Bully, from Andrea, Age 8 1 12 ," Andrea Gibson uses whimsical childhood imagery to create an imaginary confrontation between the author and the third grade boy who used to torment her. Several poets also utilize non-English words spoken in their childhood households. In the poem "What It's Like for a Brown Girl," Jessica Helen Lopez addresses the struggles she faced as a bilingual speaker in a stuffy MFA program. Lopez uses artistic license to vocalize the thoughts she believes her professors had of her: "You slam poets you, with all your hiphop and speaking in / tongues. I hope you choke on all that alliteration" (p. 133). As promised, the content of some poems carries a weight much heavier than others, meaning discussion facilitators should be prepared to navigate difficult subject matter if such poems are chosen. Tara Hardy's poem "My, My, My, My, My" offers healing encouragement to victims of rape while Jeanann Verlee's "Swarm" instructs young girls how to urgently say no to young men who have overstepped their boundaries. Video and audio of other similarly themed works by all of the contributors can be found online for educators looking to create a multimodal text set for their poetry unit.

In addition to being a Write Bloody author and editor, poet Karen Finneyfrock achieved success outside the small-press market when her first young adult novel The Sweet Revenge of Celia Door (2013) was published by Penguin Groups Viking Press. The cover art depicts a pigeon-toed girl wearing knee-high black boots and black fishnet stockings, with folded arms and a head conveniently cut off by the top of the page. Celia 
Door is a friendless fourteen-year-old girl tasked with navigating through catty school hall politics and her parents' impending divorce. Incessant teasing and bullying has urged Celia to "turn Dark," meaning she's adopted a Goth identity with black eyeliner and skull hoodies. While young adult books commonly use toxic tropes to depict members of Goth culture as whiny, cynical, and emotionally unstable, Celia stands in stark contrast as an earnest, relatable, lonely little girl whose only wish is to find a friend. "When I say I turned Dark, what I really mean is that I gave up. I gave up on trying to fit in and make everyone like me ... I realized that, in a field of sunflowers, I'm a black-eyed Susan" (Finneyfrock, 2013, p. 7). While a majority of the novel is told through prose, the chapters are peppered with little notes and poems that Celia writes to herself in her journal-which could lend themselves to prompted classroom short writing responses. The young protagonist even utilizes metaphors to help the reader internalize the emotional implications of plot points in the story. "All you need is one friend and suddenly a weekend looks like a wide-open field" (Finneyfrock, 2013, p. 138). Celia's luck changes when a cool, handsome kid from New York name Drake moves to town and befriends her. Though the relationship begins as a love interest for Celia, Finneyfrock flips the young adult trope on its head when Drake admits to Celia that he is gay. Although she is initially crushed, the well-read Celia helps Drake learn more about LGBTQ culture by taking him to the library to learn about the Stonewall Riots and the anti-AIDS activist group ACT UP. When Celia attempts to take revenge against her middle school tormentors, her plans backfire, and as a result Drake's sexuality is outed in front of the entire school. Feeling the brunt of the backlash Celia learns a valuable lesson about the responsibilities of friendship. The Sweet Revenge of Celia Door tackles themes such as self-esteem and suicide, and Celia's perspective could be a fresh way to approach a classroom conversation about the impacts of bullying.

Hopefully, more large-scale publishers will pay attention to artists from the slam community. Karen Finneyfrock's second book of prose for young adults, Starbird Murphy and the Outside World, was released by Viking in June 2014, which is a testament to her success at entering the young adult market. Representation in both large and small presses is vital for a healthy arts movement, so it is also important that poetry patrons support the young adult efforts of independent presses like Write Bloody. If publishers recognize that there is a desire for more young adult works written by slammers, perhaps they will be willing to take risks by giving new authors a chance.

\section{Hear This Book with Your Eyes}

This article is just an initial attempt to familiarize educators with the conventions of spoken word written for young adult audiences. Though some poetry from the slam circuit is captured on YouTube videos or Compact Discs, literacy educators should not feel discouraged from approaching the written work of slammers through conventional textual analysis. The best advice I can give to educators is to turn their reading instruction into a multimodal learning process (Cazden et al, 1996; Ong, 1980) by reading poems out loud, listening to audio and watching video along with reading texts, crafting written responses, drawing pictures and text on graffiti boards, discussing the content of poems in small and large groups, and even facilitating a classroom poetry slam tackling themes discussed in shared work. Although educators should feel encouraged to treat artists from the community as a resource, it is imperative that teachers avoid quick fixes and familiarize 
themselves with the arts community they intend to promote. While this article more or less serves as a comprehensive review of notable slam works marketed as young adult literature, there are thousands and thousands of poems written for adult audiences that could also be effective in the classroom. Educators who wish to dive deeper into the slam medium should feel encouraged to use the works cited in this literature review to learn more about spoken word and its artists.

It is also beneficial for young adult publishers to embrace populist movements like slam that are commonly revered for their inclusion of diverse artists (Somers-Willett, 2008). A study of the 2013 New York Times Young Adult Best Sellers List revealed that only $15 \%$ of main characters were nonwhite, only $13 \%$ of overall characters were LGBTQ and only 3\% of overall characters were disabled (Lo \& Pon, 2014). The multicultural artists from the slam community could help meet the public demand for literature that features diverse characters; however, the authors featured in this literature review are a poor representation of slam's overall diversity, which suggests that nonwhite authors from the slam circuit have faced similar barriers in regards to being supported by young adult publishing companies. The cost of not being represented in academic and literary institutions means that many artists from the slam community are not being canonized.

As a spoken word practitioner tasked with assessing my own biases (Peshkin, 1988), I welcome additional research and discourse from academics and educators who are further removed from the community. While other researchers may need convincing, I know that spoken word can save lives, because it saved mine when I was sixteen years old. I'm sure the educator who placed that copy of Aloud in my hands had no idea how far that book would take me. Those of us who were inspired by the anthology know the power of placing poetry in the palms of a young person, and it is the duty of this poet-that-myyounger-self-needed to ensure that the youth of today do not walk away empty-handed.

\section{References}

Abbott, B. (2008). Let them eat MoonPie. Whitmore Lake, MI: Wordsmith Press.

Algarín, M., \& Holman, B. (1994). Aloud: Voices from the Nuyorican poet's cafe. New York: Holt Paperbacks.

Aptowicz, C.0. (2008). Words in your face: A guided tour through twenty years of the New York poetry slam. New York: Soft Skull Press.

Aptowicz, C.O. (2009). Funny poetry gets slammed: Humor as strategy in the poetry slam movement. International Journal of Humor Research, 22(3), 381-393.

Biggs-El, C. (2012). Spreading the indigenous gospel of rap music and spoken word poetry: Critical pedagogy in the public sphere as a stratagem of empowerment and critique. The Western Journal of Black Studies, 36(2), 161-168.

Brawley, L. (1994). The virtual slam: Performance poetry on the net. Chicago Review, 40(2), 164-175.

Bruce, H.E., \& Davis, B.D. (2000). Slam: Hip-hop meets poetry-a strategy for violence intervention. The English Journal, 89(5), 119-127. 
Cazden, C., Cope, B., Fairclough, N., Gee, J., Kalantzis, M., Kress, G., ... Nakata, M. (1996). A pedagogy of multiliteracies: Designing social futures. Harvard Educational Review, 66(1), 60-92.

Cline, E. (2011). Ready player one. New York: Crown Publishers.

Eleveld, M. (2003). The spoken word revolution: Slam, hip-hop \& the poetry of a new generation. Naperville, IL: Sourcebooks MediaFusion.

Ellis, L., Gere, A.R., \& Lamberton, L.J. (2003). Out loud: The common language of poetry. The English Journal, 93(1), 44-49.

Erlich, R. (1999, February 9). Teens get creative for poetry slam 'lite'. Christian Science Monitor, 91, 16.

Finneyfrock, K. (2013). The sweet revenge of Celia Door. New York: Viking.

Finneyfrock, K., McKibbens, R., \& Nettifee, M. (2014). Courage: Daring poems for gutsy girls. Austin, TX: Write Bloody Publishing.

Fisher, M.T. (2007). Writing in rhythm: Spoken word poetry in urban classrooms. New York: Teachers College Press.

Gardner, H. (1983). Frames of mind: The theory of multiple intelligences. New York: BasicBooks.

Gioia, D. (2002). Can poetry matter? In D. Gioia (Ed.), Can poetry matter? Essays on poetry and American culture (pp. 1-24). Saint Paul, MN: Graywolf.

Gomez, C. A. (2012). Man up: Cracking the code of modern manhood. New York: Gotham.

Hanisch, C. (1970). The personal is political. In S. Firestone \& A. Koedt (Eds.), Notes from the Second Year: Womens Liberation, Major Writings of the Radical Feminists. New York: Radical Feminism.

Harlan, M.A. (2008). Poetry slams go digital. CSLA Journal, 31(2), 20-21.

Holbrook, S. (1998). Walking on the boundaries of change: Poems of transition. Honesdale, PA: Boyds Mills Press.

Holbrook, S., \& Salinger, M. (2006). Outspoken: How to improve writing and speaking skills through poetry performance. Portsmouth, NH: Heinemann.

Holbrook, S., \& Wolf, A. (2008). More than friends: Poems from him and her. Honesdale, PA: Wordsong.

Ingalls, R. (2012). "Stealing the air": The poet-citizens of youth spoken-word. The Journal of Popular Culture, 45(1), 99-117.

Johnson, D. (1988, March 3). Chicago Journal: It's pure poetry, for cheers or jeers. The New York Times. Retrieved from http://www.nytimes.com/1988/03/03/us/chicagojournal-it-s-pure-poetry-for-cheers-or-jeers.html/.

Kaufman, A. (1999). The outlaw bible of American poetry. New York: Thunder's Mouth Press. 
Koyczan, S. (2012). Stickboy: A novel in verse (2nd ed.). Vancouver: McKellar \& Martin.

Koyczan, S. (2013, Feb.). To this day ... for the bullied and the beautiful. Ted Talk retrieved from https://www.ted.com/talks/shane koyczan to this day for the bullied and beautif ul?language $=e n$

Lacatus, C. (2009). Visual identies of the other: Performance art and the public sphere in contemporary Sweden. Scandinavian Studies, 81(4), 475-500.

Lo, M., \& Pon, C. (2014, April 25). Diversity in 2013 New York Times Young Adult Bestsellers. Retrieved from http://diversityinya.tumblr.com/tagged/statistics.

Low, B.E. (2011). Slam school: Learning through conflict in the hip-hop and spoken word classroom. Stanford, CA: Stanford University Press.

McDaniel, J. (2000). Slam and the academy. In G.M. Glazner (Ed.), Poetry slam: The competitive art of performance poetry (pp. 35-37.). San Francisco, CA: Manic D Press.

Michael, P. (2001). The teen poetry explosion. Writing, 24(2), 4-7.

Ong, W.J. (1980). Literacy and orality in our times. Journal of Communication, 30(1), 197204.

Peshkin, A. (1988). In search of subjectivity-One's own. Educational Researcher, 17(7), $17-21$.

Poole, S. (2007). 'Slambiguité'? Youth culture and the positioning of 'le slam' in France. Modern \& Contemporary France, 15, 339-350.

Rosenthal, M.L. (1959, September 19). Poetry as confession. The Nation, 189, 154-155.

Rudd, L. (2012). Just slammin! Adolescents' construction of identity through performance poetry. Journal of Adolescent \& Adult Literacy, 55(8), 682-681.

Sibley, R.L. (2001). Oral poetry in a literate culture: A performance ethnography of poetry slams (Doctoral dissertation). Retrieved from ProQuest (3021452).

Somers-Willett, S. B. A. (2008). Can slam poetry matter? Rattle, 27, 85-90.

Somers-Willett, S. B. A. (2009). The cultural politics of slam poetry: Race, identity, and the performance of popular verse in America. Ann Arbor, MI: The University of Michigan Press.

Smith, M.K., \& Kraynak, J. (2004). The complete idiot's guide to slam poetry. Indianapolis, IN: Alpha Books.

Smith, M., \& Kraynak, J. (2009). Take the mic: The art of performance poetry, slam, and the spoken word. Naperville, IL: Sourcebooks Mediafusion.

Smith, P. (2000). Persona poem. In G.M. Glazner (Ed.), Poetry slam: The competitive art of performance poetry. San Francisco: Manic D Press.

Spasic, M., Lukic, S., Bisevac, B., \& Peric, Z. A case report of a patient with epilepsy and synesthesia. HealthMed, 6, 2583-2587. 
Stafford, T., \& Brown, D. (2010). Learn then burn. Long Beach, CA: Write Bloody Publishing.

Stovall, D. (2006). Urban poetics: Poetry, social justice and critical pedagogy in education. The Urban Review, 38(1), 63-80.

Weiss, J., \& Herndon, S. (2001). Brave new voices: The Youth Speaks guide to teaching spoken word poetry. Portsmouth, NH: Heinemann.

Wolf, A. (2004). New found land: A novel. Cambridge, MA: Candlewick Press.

Wolf, A. (2007). Zane's trace. Cambridge, Mass.: Candlewick Press.

Wolf, A. (2011). The watch that ends the night: voices from the Titanic. Somerville, Mass.: Candlewick Press.

Wolf, A. (Interviewee). (2012, Apr. 13). News 13 This Weekend. ABCNews. Retrieved from https://www.youtube.com/watch?v=3nni4SGQY1U 